\title{
Norbornadiene-functionalized triazatriangulenium and trioxatriangulenium platforms
}

\author{
Roland Löw ${ }^{1}$, Talina Rusch², Tobias Moje ${ }^{1}$, Fynn Röhricht ${ }^{1}$, Olaf M. Magnussen ${ }^{\star 2}$ \\ and Rainer Herges ${ }^{* 1}$
}

\section{Full Research Paper}

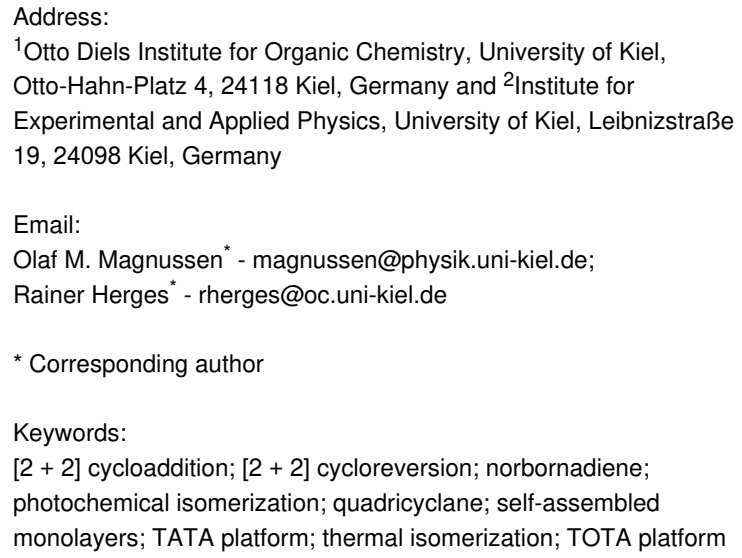

${ }^{1}$ Otto Diels Institute for Organic Chemistry, University of Kiel, Otto-Hahn-Platz 4, 24118 Kiel, Germany and ${ }^{2}$ Institute for Experimental and Applied Physics, University of Kiel, Leibnizstraße 19, 24098 Kiel, Germany

Email:

Olaf M. Magnussen* - magnussen@physik.uni-kiel.de; Rainer Herges* - rherges@oc.uni-kiel.de

${ }^{*}$ Corresponding author

Keywords:

[2 + 2] cycloaddition; [2 + 2] cycloreversion; norbornadiene; photochemical isomerization; quadricyclane; self-assembled monolayers; TATA platform; thermal isomerization; TOTA platform

\author{
Beilstein J. Org. Chem. 2019, 15, 1815-1821. \\ doi:10.3762/bjoc. 15.175 \\ Received: 11 April 2019 \\ Accepted: 17 July 2019 \\ Published: 30 July 2019 \\ This article is part of the thematic issue "Molecular switches". \\ Guest Editor: W. Szymanski \\ (C) 2019 Löw et al.; licensee Beilstein-Institut. \\ License and terms: see end of document.
}

\begin{abstract}
Triazatriangulenium (TATA) and trioxatriangulenium (TOTA) ions are particularly suited systems to mount functional molecules onto atomically flat surfaces such as $\mathrm{Au}(111)$. The TATA and TOTA units serve as platforms that absorb onto the surface and form ordered monolayers, while the functional groups are protruding upright and freestanding from the central carbon atoms. Azobenzene derivatized TATA's are known to exhibit extremely fast cis $\rightarrow$ trans isomerization on metal surfaces, via a peculiar non-adiabatic singlet $\rightarrow$ triplet $\rightarrow$ singlet mechanism. We now prepared norbornadienes (NBD) and quadricyclanes (QC) attached to TATA and TOTA platforms which can be used to check if these accelerated rates and the spin change mechanism also apply to [2 +2$]$ cycloreversions (QC $\rightarrow \mathrm{NBD})$.
\end{abstract}

\section{Introduction}

Recently, we discovered that the thermochemically forbidden cis-trans isomerization of azobenzenes can be efficiently catalysed by a very peculiar mechanism on bulk gold [1]. In heterogeneous catalysis, the surface is chemically involved in bond making and breaking. In contrast to this conventional surface catalysis the new mechanism does not involve direct contact with the surface. Electronic coupling via a conjugated $\pi$-system to the conducting band of a bulk metal is sufficient to accel- erate the rate of isomerization by three orders of magnitude [2-4]. To keep the reacting azobenzene molecule at a distance of about $14 \AA$ from the surface, it is not directly absorbed onto the surface but mounted on a carefully designed molecular framework. This approach was named the platform approach [5]. Three molecular units are combined in a modular way to achieve a controlled adsorption on the surface: the platform, a spacer and the functional molecule. Triazatriangulenium 
(TATA) and trioxatriangulenium (TOTA) units are used as molecular platforms. They adsorb on the surface and form ordered monolayers. A linear, $\pi$-conjugated spacer (e.g., an ethynyl unit) is attached to the central carbon atom and the functional molecule is mounted on top. This architecture allows investigating molecules on surfaces under controlled conditions. The size of the platforms determines the intermolecular distances and enforces an upright orientation of the free standing functional groups [6]. The length and the nature of the spacer is used to tune the distance and electronic coupling of the functional system on top [1].

Preliminary experiments proved that the electronic coupling to the surface is the decisive parameter controlling the cis-trans rate acceleration of azobenzenes and not the length of the spacer [1]. A full conjugation path from the azobenzene on top through the ethynyl spacer and the platform to a bulk gold surface shortens the half-life of the metastable cis-isomer from days to seconds even though the azo $\mathrm{N}=\mathrm{N}$ group is 11 bonds and $14 \AA$ away from the surface. A singlet $\rightarrow$ triplet $\rightarrow$ singlet pathway was suggested to explain the dramatic rate acceleration.

To obtain further insight into this unusual mechanism and to explore the scope and limitation of the general concept, we are aiming at the extension from simple cis $\rightarrow$ trans isomerization to other thermochemically forbidden reactions such as $[2+2]$ cycloreversions. Moreover, a deeper understanding of the nonadiabatic, catalytic process and successful application of the concept to the $\mathrm{QC} \rightarrow \mathrm{NBD}$ isomerization could contribute to the elucidation of the mechanisms of bulk metal catalysis and open new ways to design new catalytic systems.

Towards this end, and following the "platform concept", we designed a cyano-substituted norbornadiene, which is functionalized with an acetylene spacer on a TATA platform to investigate an eventual "spin-catalysed" [2+2] cycloreversion on bulk gold of quadricyclane $\mathbf{1 b}$ to norbornadiene 1a (Figure 1).

The cycloreversion of most quadricyclane systems proceeds smoothly in solution upon irradiation in the presence of triplet sensitizers [7]. If $\mathbf{1 b}$ is adsorbed on a gold surface the bulk gold could take the role of a triplet sensitizer, mediate the spin change (which otherwise is forbidden) and accelerate the cycloreversion. Substitution in the 2 and 3 positions shifts the bathochromic absorption to $375 \mathrm{~nm}$ which is in agreement with similar systems [8]. Furthermore, the cyano and ethynyl groups provide a complete conjugation path across the double bond of norbornadiene to the metal. Additionally, it is known that electron-withdrawing groups in 2 or 3 position change the triplet energy hypersurface in such a way that a triplet excited quadri-

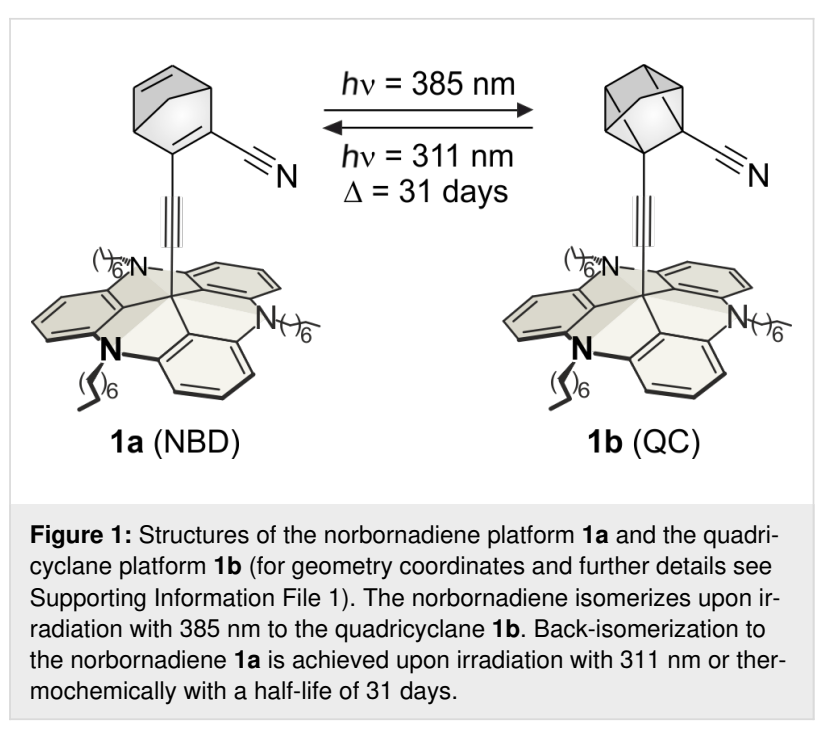

cyclane $\mathbf{1 b}$ decays into the ground state of the norbornadiene 1a [9], which is a precondition for an efficient QC $\rightarrow$ NBD isomerization via our postulated non-adiabatic singlet $\rightarrow$ triplet $\rightarrow$ singlet mechanism.

\section{Results and Discussion}

If our proposed spin change mechanism, mediated by the conducting electrons in bulk gold were correct, interruption of the conjugation path and decoupling from the surface should restore the properties of the system (half-life of the metastable quadricyclane) in solution. According to this line of thought, we synthesized molecule $\mathbf{2}$ with a 2-methylphenyl group inserted into the spacer unit (see below Scheme 2). The methyl group prevents a planar arrangement of the phenyl group and the double bond of the NBD unit and thus lowers the conjugation.

We also synthesized the corresponding system directly connected to a TOTA platform 3 . Functionalized TOTA molecules are more stable than the corresponding TATA systems and usually can be sublimed without decomposition, which is a necessary precondition for ultra-high vacuum STM investigations.

The 3-bromo-2-cyano-substituted norbornadiene $\mathbf{4}$ was synthesized as described in the literature (Scheme 1) [10-12].

4 was converted to 5 with trimethylsilylacetylene (72\%) in a Sonogashira cross-coupling reaction. The triazatriangulenium ion 6 was synthesized according to a procedure of Laursen and Krebs [13]. The platform 6 was functionalized with norbornadiene 5 by deprotection of the acetylene with potassium hydroxide and in situ formation of the $\mathrm{C}-\mathrm{C}$ bond between the acetylene and the central $\mathrm{C}$ atom of the platform $\mathbf{6}$ to yield the norbornadiene-substituted platform $1(62 \%)$. 


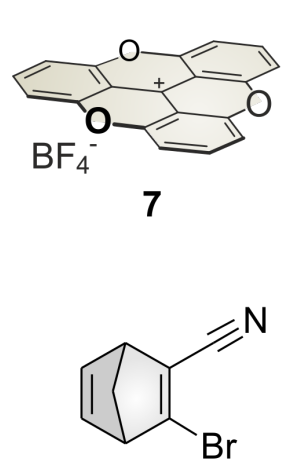

4

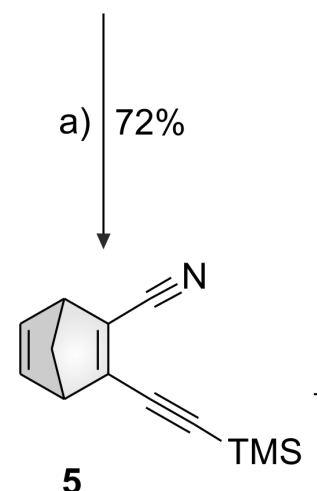

c)

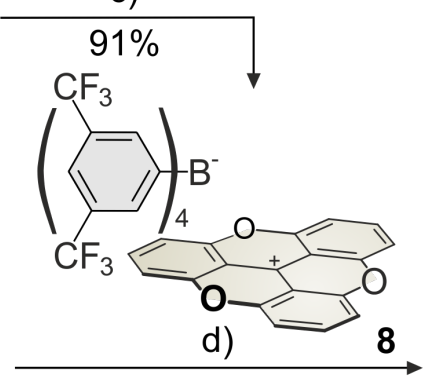

$22 \%$

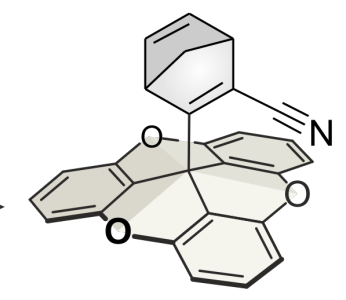

3

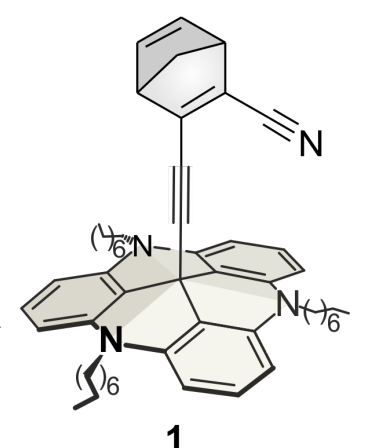

1

Scheme 1: Syntheses of the norbornadiene TATA platform 1 and TOTA platform 3. a) TMS-acetylene, $\mathrm{Pd}\left(\mathrm{PPh}_{3}\right)_{4}, \mathrm{Cu}(\mathrm{l}) \mathrm{I}, \mathrm{Et}{ }_{3} \mathrm{~N}$, toluene, $\mathrm{N}_{2}, 60{ }^{\circ} \mathrm{C}$, $1.3 \mathrm{~h}$; b) $\mathrm{KOH}, \mathrm{THF}, \mathrm{N}_{2}$, reflux, $5 \mathrm{~h}$; c) sodium tetrakis[3,5-bis(trifluoromethyl)phenyl]borate ( $\mathrm{NaBArF}_{4}$ ), DCM, rt, $2 \mathrm{~h}$; d) $n$-BuLi, THF, $\mathrm{N}_{2},-78^{\circ} \mathrm{C}$ to rt, $20 \mathrm{~h}$.

The TOTA cation with the tetrakis(3,5-bis(trifluoromethyl)phenyl)borate anion $\left(\mathrm{TOTA}^{+}\left[\mathrm{BAr}_{4}\right]^{-}, \mathbf{8}\right)$ was obtained by ion exchange of the TOTA tetrafluoroborate $7\left(\mathrm{TOTA}^{+} \mathrm{BF}_{4}^{-}\right)$to achieve a high solubility in organic solvents [14]. 3-Bromo-2cyanonorbornadiene (4) was subjected to halogen-metal exchange with $n$-BuLi and coupled with the central atom of the
TOTA platform 8 to obtain the norbornadiene-functionalized TOTA platform 3 (22\%, Scheme 1). The synthesis of the corresponding TATA platform including an additional 2-methylphenyl group (2) was obtained in a convergent synthesis (Scheme 2). Boronic ester 9 was synthesized as described in the literature [15]. In a Suzuki cross-coupling reaction norborna-
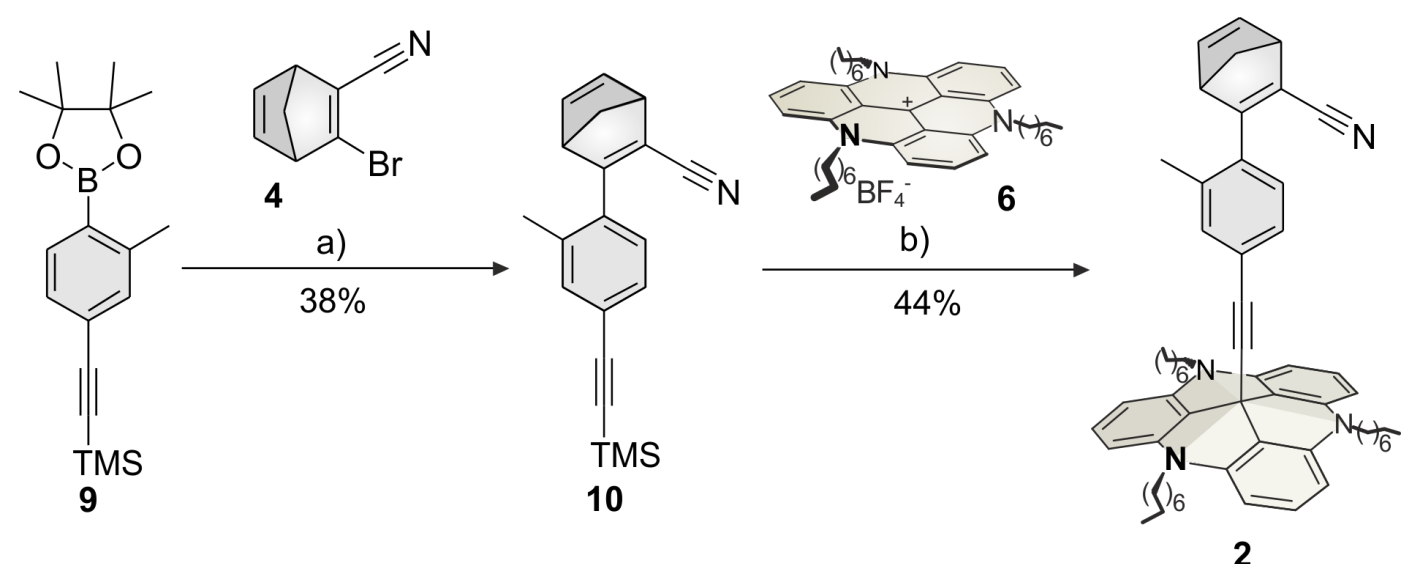

Scheme 2: Synthesis of methylphenylnorbornadiene platform 2. a) $\mathrm{Pd}\left(\mathrm{PPh}_{3}\right)_{4}, \mathrm{Na}_{2} \mathrm{CO}_{3}$, toluene, $\mathrm{EtOH}, \mathrm{H}_{2} \mathrm{O}, \mathrm{N}_{2}$, reflux, 12 h; b) $\mathrm{KOH}, \mathrm{THF}, \mathrm{N}_{2}$, reflux, $1 \mathrm{~h}$. 
diene $\mathbf{4}$ was coupled with 9 to the extended norbornadiene 10 (38\%), which was attached to the TATA platform 6 to yield the extended norbornadiene platform 2 (44\%).

The photophysical properties and the switching behaviour of $\mathbf{1}$, $\mathbf{2}$ and $\mathbf{3}$ were determined in solution (THF). The UV-vis spectra of the norbornadienes (NBD, black, 1a, 2a, 3a) and quadricylanes (QC, red, $\mathbf{1 b}, \mathbf{2} \mathbf{b}, \mathbf{3 b}$ ) and the spectra of the QCs after irradiation with $311 \mathrm{~nm}$ for $\mathbf{1 b}$ and $\mathbf{2 b}$ or $254 \mathrm{~nm}$ for $\mathbf{3 b}$ (blue) are shown in Figure 2. The bathochromic absorption maximum of norbornadiene 1a is at $375 \mathrm{~nm}$ (as compared to $<300 \mathrm{~nm}$ in parent norbornadiene) $[16,17]$. The absorption maximum of quadricyclane $\mathbf{1 b}$ is at $336 \mathrm{~nm}$ (as compared to $187 \mathrm{~nm}$ in parent quadricyclane) [18]. The weak and broad absorption band with a maximum at $524 \mathrm{~nm}$ is due to the TATA cation generated by decomposition during irradiation with $311 \mathrm{~nm}$.

The photostationary states were determined in deuterated oxygen containing deuterated benzene and degassed deuterated benzene by ${ }^{1} \mathrm{H}$ NMR measurements (Figure 3). Norbornadiene 1a isomerizes quantitatively to quadricyclane $\mathbf{1 b}$ by irradiation with $385 \mathrm{~nm}$. Upon irradiation of $\mathbf{1 b}$ under nitrogen with $311 \mathrm{~nm}$, the cycloreversion yields $28 \%$ norbornadiene (Table 1).

The efficiency of the cycloreversion is higher under air (52\%), however, slow decomposition was observed (cleavage of the TATA $^{+}$platform). Obviously, in the presence of oxygen, the photochemical cycloreversion proceeds via a triplet radical mechanism. This agrees with observations described in the literature [16]. In degassed benzene neither 1a nor 1b exhibits decomposition upon repeated irradiation with $385 \mathrm{~nm}$ and $311 \mathrm{~nm}$.

The thermal isomerization of QC 1b back to NBD 1a was investigated by ${ }^{1} \mathrm{H}$ NMR measurements (Figure 4).

The cycloreversion follows a first order reaction, the rate constant could be determined by logarithmic fitting of the integrals of the $\mathrm{CH}_{2}$ signals next to the nitrogen atoms of the platform as

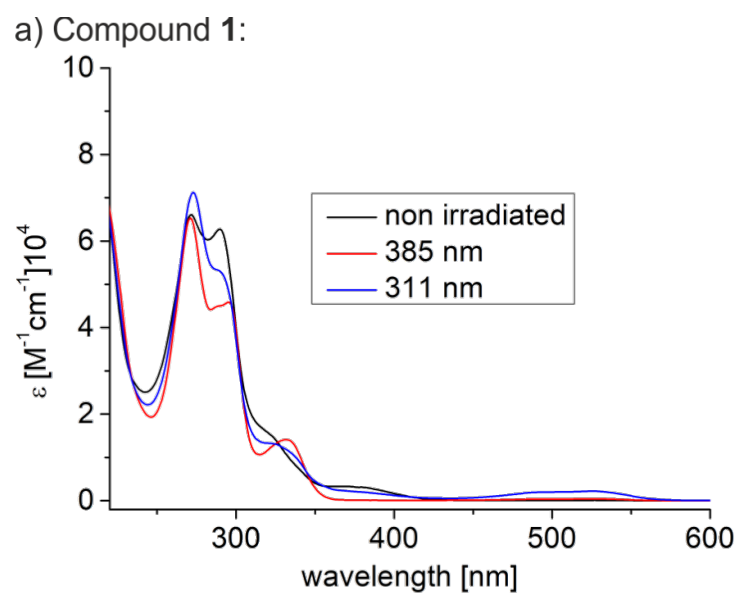

c) Compound 3:

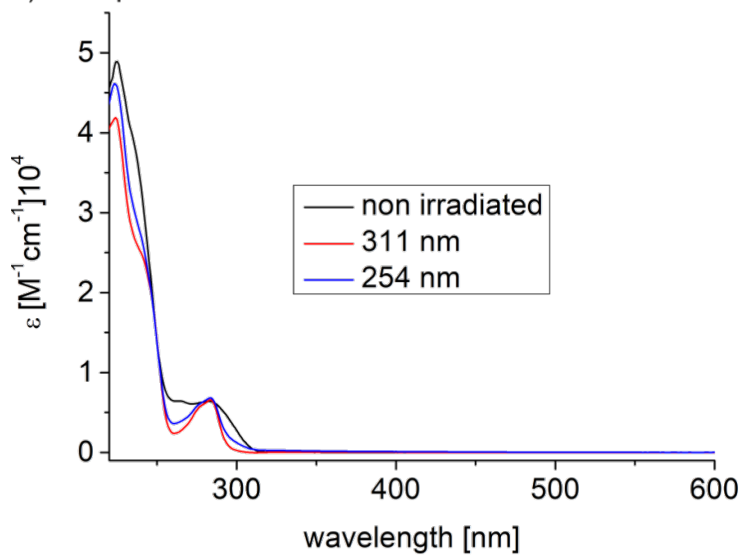

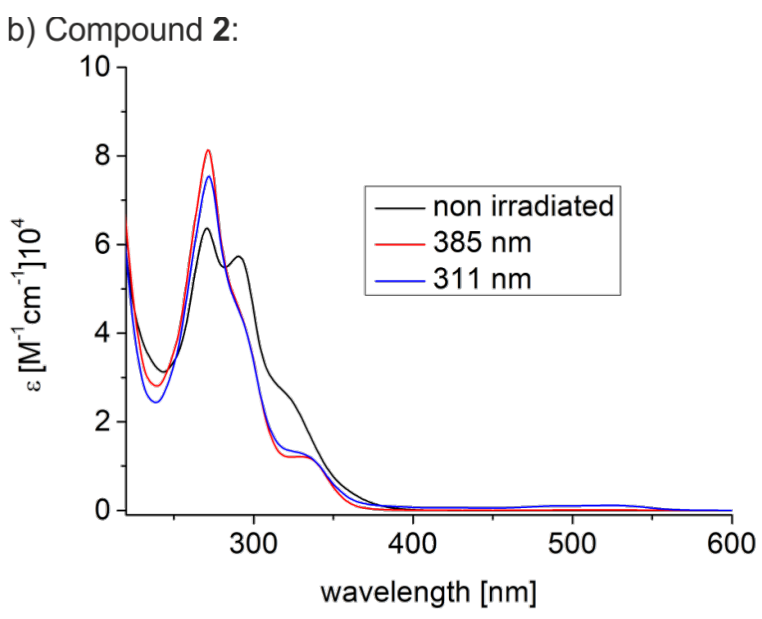

Figure 2: UV-vis spectra of platform molecules 1 (a), 2 (b) and $\mathbf{3}$ (c) (in THF at rt): Norbornadiene (black), quadricyclane (red) and after irradiation with $311 \mathrm{~nm}$ (compound $\mathbf{1 b}$ and $\mathbf{2 b}$ ) or $254 \mathrm{~nm}$ (compound $\mathbf{3 b}$ ) for $2.5 \mathrm{~min}$ (blue). 

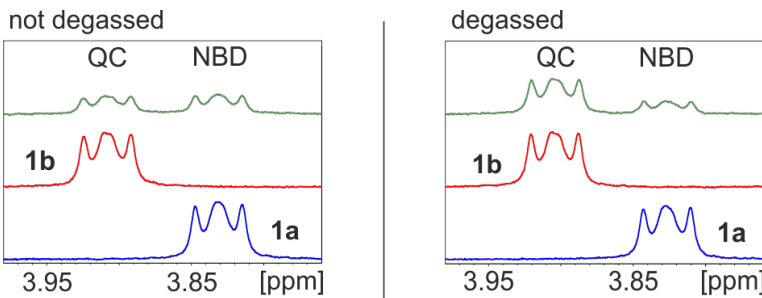

Figure 3: ${ }^{1} \mathrm{H}$ NMR spectra of 1 in deuterated oxygen containing deuterated benzene (left) and degassed deuterated benzene (right). Shown are the signals of the $\mathrm{CH}_{2}$ groups of the alkyl side chains next to the nitrogen atoms in the TATA platforms, which are indicative of the isomerization. Left bottom (blue): non-irradiated NBD 1a; left middle (red): pure QC 1b obtained after irradiation of $\mathbf{1 b}$ with $385 \mathrm{~nm}$ for one minute; and left top (green): photostationary state of $\mathbf{1 a}$ and $\mathbf{1 b}$ after $1 \mathrm{~h}$ irradiation with $311 \mathrm{~nm}$ under air $(52 \% 1 \mathrm{a} / 48 \% 1 \mathrm{~b})$. Right bottom (blue): pure NBD 1a; right middle (red): pure QC 1b obtained after irradiation of 1a with $385 \mathrm{~nm}$ for one minute and right top (green): photostationary state of $\mathbf{1 a}$ and $\mathbf{1 b}$ after $2 \mathrm{~h}$ irradiation with $311 \mathrm{~nm}$ under nitrogen atmosphere $(28 \% 1 \mathrm{a} / 72 \% 1 \mathrm{~b})$.

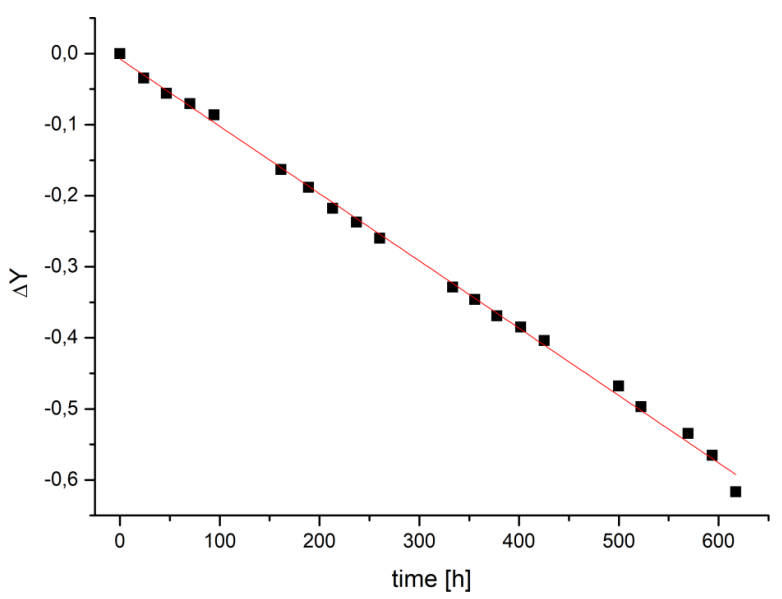

Figure 4: Determination of the thermal isomerization rate $k$ of $1 \mathbf{b}(\mathrm{QC})$ by ${ }^{1} \mathrm{H}$ NMR spectroscopy (toluene, $293.5 \mathrm{~K}, 800 \mu \mathrm{mol} / \mathrm{L}$, under nitrogen). $\Delta \mathrm{Y}:$ In $\left\{[\mathrm{QC}]_{\mathrm{t}} /[\mathrm{QC}]_{0}\right\},[\mathrm{QC}]_{\mathrm{t}}:{ }^{1} \mathrm{H}$ NMR integral of the $\mathrm{CH}_{2}$ group neighbouring the $\mathrm{N}$ bridge atom of the TATA platform in QC 1b at time $t,[\mathrm{QC}]_{0}$ corresponding ${ }^{1} \mathrm{H}$ integral at $t=0$. A rate constant of $k=0.95 \cdot 10^{-3} \mathrm{~s}^{-1}$ was determined from a linear fit of the $\Delta \mathrm{Y} / \mathrm{t}$ curve. $k=1.06 \cdot 10^{-3} \mathrm{~s}^{-1}$ under air and $0.95 \cdot 10^{-3} \mathrm{~s}^{-1}$ under nitrogen. Hence, the thermal reaction (in contrast to the photochemical reaction) is not largely affected by oxygen. The half-life of the metastable quadricyclane is $t_{1 / 2}=655 \mathrm{~h}$ in benzene under air at $293 \mathrm{~K}$ (Table 1). Minor amounts of degradation products $(<1 \%)$ after following the cycloreversion within a period of one month are visible in the ${ }^{1} \mathrm{H}$ NMR spectrum. Under nitrogen atmosphere the half-life of the cycloreversion is $t_{1 / 2}=732 \mathrm{~h}(294 \mathrm{~K})$.

The rate constant as a function of the temperature follows an Arrhenius-type relationship. The activation energy for the cycloreversion was determined by linear fit of $\ln (k)$ as a function of $1 / T$. The cycloreversion of QC $\mathbf{1 b}$ to NBD 1a has an activation energy of $111 \mathrm{~kJ} \mathrm{~mol}^{-1}$ (degassed deuterated benzene). The switching efficiency of NBD $\mathbf{2 a}$ to QC $\mathbf{2 b}$ is quantitative $(\approx 100 \%)$ after irradiation with $385 \mathrm{~nm}$, whereas the photostationary state of NBD 3a to QC $\mathbf{3 b}$ is lower with $91 \%$.

No thermal cycloreversion of the quadricyclanes $\mathbf{2 b}$ and $\mathbf{3 b}$ was observed at room temperature within a period of one month. Obviously, a cyano as well as a neighbouring ethynyl substituent are necessary to induce the back-isomerisation at ambient conditions as realized in compound $\mathbf{1}$. Consequently, future surface chemistry investigations will be performed with compound $\mathbf{1}$ including the TATA platform and an ethynyl spacer.

\section{STM Measurements}

The adsorption behaviour of the NBD 1a on Au(111) surfaces was studied by scanning tunnelling microscopy (STM) at room temperature (Figure 5a). The molecules form a hexagonally ordered self-assembled monolayer (SAM) with an intermolecular distance of $(1.23 \pm 0.07) \mathrm{nm}$. This is in agreement with a $(\sqrt{19} \times \sqrt{19}) \mathrm{R} 23.4^{\circ}$ superstructure, which was observed in our previous investigations of adlayers of octyl-TATA derivatives [1,6,19-21]. Two types of molecules with a distinct difference in apparent height of $\approx 1 \AA$ were observed in the STM images (Figure $5 \mathrm{~b}$ ). Both types of molecules are located at identical positions of the $(\sqrt{ } 19 \times \sqrt{ } 19)$ R $23.4^{\circ}$ lattice and seem to be distri-

Table 1: Photostationary states (PSS) of norbornadiene platforms $\mathbf{1}, \mathbf{2}$ and $\mathbf{3}$ upon irradiation with light of the wavelengths $\boldsymbol{\lambda}_{\text {irrad }}=385 \mathrm{~nm}(\mathbf{1 a}, \mathbf{2 a})$ or $311 \mathrm{~nm}(\mathbf{3 a})$ and $311 \mathrm{~nm}(\mathbf{1 b}, \mathbf{2 b})$ or $254 \mathrm{~nm}(\mathbf{3 b})$ and the thermal isomerization half-life $t_{1 / 2}$ determined by ${ }^{1} \mathrm{H}$ NMR spectroscopy (deuterated benzene under air/degassed deuterated benzene).

\begin{tabular}{|c|c|c|c|c|c|}
\hline Compound & atmosphere & $\begin{array}{c}\text { PSS } \\
\% \text { QC }\left(\lambda_{\text {irrad }}\right)\end{array}$ & $\begin{array}{c}\text { PSS } \\
\% \operatorname{NBD}\left(\lambda_{\text {irrad }}\right)\end{array}$ & $t_{1 / 2}(\mathrm{~h})$ & $\begin{array}{c}\mathrm{EA} \\
\mathrm{kJ} / \mathrm{mol}\end{array}$ \\
\hline 1 & air & $\approx 100(385 \mathrm{~nm})$ & $52(311 \mathrm{~nm})$ & $655(293 \mathrm{~K})$ & I \\
\hline 1 & $\mathrm{~N}_{2}$ & $\approx 100(385 \mathrm{~nm})$ & $28(311 \mathrm{~nm})$ & $732(294$ K) & 111 \\
\hline 2 & $\mathrm{~N}_{2}$ & $\approx 100(385 \mathrm{~nm})$ & 48 (311 nm) & $>1$ year & I \\
\hline 3 & $\mathrm{~N}_{2}$ & $91(311 \mathrm{~nm})$ & $33(254 \mathrm{~nm})$ & $>1$ year & l \\
\hline
\end{tabular}



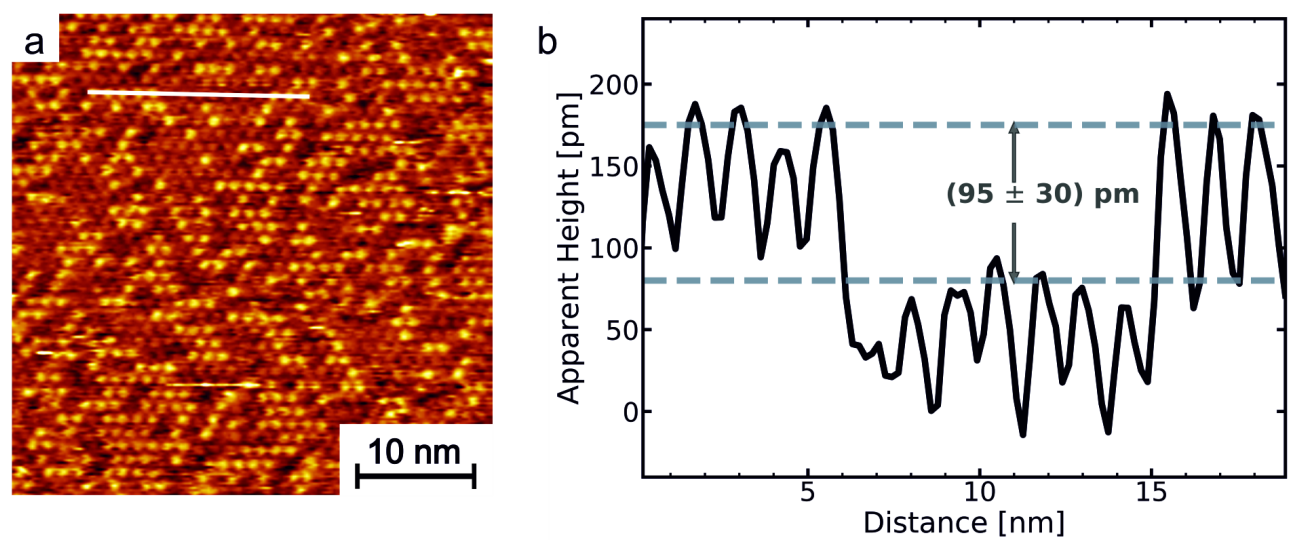

Figure 5: (a) STM image of self-assembled monolayers of compound 1 on $\mathrm{Au}(111)\left(40 \times 40 \mathrm{~nm}^{2}, I_{\mathrm{t}}=0.05 \mathrm{nA}, U_{\text {bias }}=0.40 \mathrm{~V}\right)$ and $(\mathrm{b})$ crossection along the white line in (a).

buted rather randomly on the surface. Two explanations are possible to account for the presence of these two species: Either they correspond to a mixture of adsorbed NBD-TATA 1a and QC-TATAs 1b or to coadsorption of 1a and the pure octylTATA 6 . The first case may be possible, because the molecules are able to switch to the $\mathbf{1 b}$ state at a wavelength of $385 \mathrm{~nm}$ and the substance was exposed to daylight during preparation and incorporation into the STM. However, since the ratio on the surface is $42 \%$ for molecules with a greater apparent height and $58 \%$ for molecules with a lower apparent height, this assumption is unlikely as at least $42 \%$ of the molecules would have to be in the switched state $\mathbf{1 b}$. The second explanation, i.e., that the mixed monolayer consists of octyl-TATA 6 and the NBDTATA 1a, seems to be more likely, since molecule $\mathbf{1}$ decays slowly under irradiation in contact with oxygen. Previous measurements have shown that self-assembly from solutions containing pure and vertically functionalized TATA molecules leads to the formation of stochastically mixed monolayers with a highly ordered $(\sqrt{ } 19 \times \sqrt{ } 19) \mathrm{R} 23.4^{\circ}$ superstructure [22]. This would be also expected for self-assembly from solution containing 1a and 6. The composition of the adlayer on the surface does not necessarily have to be identical to the ratio of the two species in solution. In fact, in our previous study the fraction of adsorbed octyl-TATA 6 as compared to that of the functionalized TATA was found to be much higher than the ratio in solution. We attributed this to the smaller size of $\mathbf{6}$ and its correspondingly higher diffusion coefficient, which results in faster transport to the Au surface and accordingly enhanced surface coverages. Thus, even low decay rates of 1a may lead to sufficiently high concentrations of $\mathbf{6}$ for obtaining mixed adlayers. By varying the preparation conditions, e.g., performing the preparation in a nitrogen atmosphere, decomposition might be avoided and monolayers of better quality could be achievable.

\section{Conclusion}

In summary, we present the syntheses of three different norbornadiene functionalized platform molecules 1-3. The photochemical switching between the norbornadiene and quadricyclane isomers with two different wavelengths was investigated. Norbornadienes $\mathbf{1}$ and $\mathbf{2}$ are quantitatively converted to the corresponding quadricyclanes upon irradiation with light of $385 \mathrm{~nm}$. Back-isomerization with $311 \mathrm{~nm}$ to the norbornadiene isomer 1a is less efficient (52\%). The high-energy quadricyclane isomer $\mathbf{1 b}$ is thermochemically unstable at room temperature (half-life $31 \mathrm{~d}$ at $21{ }^{\circ} \mathrm{C}$ in benzene) only if a cyano as well as an ethynyl substituent are present. No thermal conversion under ambient conditions was observed for $\mathbf{2}$ and $\mathbf{3}$, which are lacking ethynyl substitution. Further studies will be devoted to the surface chemistry of these compounds. Norbornadiene 1 forms highly ordered monolayers on $\mathrm{Au}(111)$ surfaces with two different apparent heights. It is not clear if a mixture of norbornadiene 1a and quadricyclane $\mathbf{1 b}$ or norbornadiene $\mathbf{1 a}$ and octyl-TATA 6 form these mixed monolayers.

\section{Experimental}

For detailed experimental procedures, including NMR, UV-vis, MS spectra and STM measurements see Supporting Information File 1, chapters I-IV, and for kinetic studies see chapter V.

\section{Supporting Information}

\section{Supporting Information File 1}

Experimental and analytical data.

[https://www.beilstein-journals.org/bjoc/content/ supplementary/1860-5397-15-175-S1.pdf] 


\section{Acknowledgements}

The authors gratefully acknowledge financial support by the Deutsche Forschungsgesellschaft within the Sonderforschungsbereich 677, "Function by Switching".

\section{ORCID ${ }^{\circledR}$ iDs}

Roland Löw - https://orcid.org/0000-0002-3051-7831

Fynn Röhricht - https://orcid.org/0000-0001-9935-9256

Rainer Herges - https://orcid.org/0000-0002-6396-6991

\section{Preprint}

A non-peer-reviewed version of this article has been previously published as a preprint doi:10.3762/bxiv.2019.5.v1

\section{References}

1. Schlimm, A.; Löw, R.; Rusch, T.; Röhricht, F.; Strunskus, T.; Tellkamp, T.; Sönnichsen, F.; Manthe, U.; Magnussen, O.; Tuczek, F.; Herges, R. Angew. Chem., Int. Ed. 2019, 58, 6574-6578. doi:10.1002/anie.201814342

2. Jung, U.; Schütt, C.; Filinova, O.; Kubitschke, J.; Herges, R.; Magnussen, O. J. Phys. Chem. C 2012, 116, 25943-25948. doi:10.1021/jp310451c

3. Jacob, H.; Ulrich, S.; Jung, U.; Lemke, S.; Rusch, T.; Schütt, C.; Petersen, F.; Strunskus, T.; Magnussen, O.; Herges, R.; Tuczek, F. Phys. Chem. Chem. Phys. 2014, 16, 22643-22650. doi:10.1039/c4cp03438d

4. Bronner, C.; Tegeder, P. New J. Phys. 2014, 16, 053004. doi:10.1088/1367-2630/16/5/053004

5. Baisch, B.; Raffa, D.; Jung, U.; Magnussen, O. M.; Nicolas, C.; Lacour, J.; Kubitschke, J.; Herges, R. J. Am. Chem. Soc. 2009, 131, 442-443. doi:10.1021/ja807923f

6. Ulrich, S.; Jung, U.; Strunskus, T.; Schütt, C.; Bloedorn, A.; Lemke, S.; Ludwig, E.; Kipp, L.; Faupel, F.; Magnussen, O.; Herges, R. Phys. Chem. Chem. Phys. 2015, 17, 17053-17062. doi:10.1039/c5cp01447f

7. Nishino, H.; Toki, S.; Takamuku, S. J. Am. Chem. Soc. 1986, 108, 5030-5032. doi:10.1021/ja00276a067

8. Quant, M.; Lennartson, A.; Dreos, A.; Kuisma, M.; Erhart, P.; Börjesson, K.; Moth-Poulsen, K. Chem. - Eur. J. 2016, 22, 13265-13274. doi:10.1002/chem.201602530

9. Ikezawa, H.; Kutal, C.; Yasufuku, K.; Yamazaki, H. J. Am. Chem. Soc. 1986, 108, 1589-1594. doi:10.1021/ja00267a032

10. Kenndoff, J.; Polborn, K.; Szeimies, G. J. Am. Chem. Soc. 1990, 112, 6117-6118. doi:10.1021/ja00172a031

11. Tranmer, G. K.; Yip, C.; Handerson, S.; Jordan, R. W.; Tam, W. Can. J. Chem. 2000, 78, 527-535. doi:10.1139/v00-047

12. Gunes, Y.; Arcelik, N.; Sahin, E.; Fleming, F. F.; Altundas, R. Eur. J. Org. Chem. 2015, 6679-6686. doi:10.1002/ejoc.201500895

13. Laursen, B. W.; Krebs, F. C. Chem. - Eur. J. 2001, 7, 1773-1783. doi:10.1002/1521-3765(20010417)7:8<1773::aid-chem17730>3.0.co;2$\mathrm{f}$

14. Martin, J. C.; Smith, R. G. J. Am. Chem. Soc. 1964, 86, 2252-2256. doi:10.1021/ja01065a030

15. Browne, D. L.; Baumann, M.; Harji, B. H.; Baxendale, I. R.; Ley, S. V. Org. Lett. 2011, 13, 3312-3315. doi:10.1021/ol2010006
16. Gray, V.; Lennartson, A.; Ratanalert, P.; Börjesson, K.; Moth-Poulsen, K. Chem. Commun. 2014, 50, 5330-5332. doi:10.1039/c3cc47517d

17. Dilling, W. L. Chem. Rev. 1966, 66, 373-393. doi: $10.1021 / \mathrm{cr60242a002}$

18. Srinivasan, R.; Baum, T.; Epling, G. J. Chem. Soc., Chem. Commun. 1982, 437-438. doi:10.1039/c39820000437

19. Hammerich, M.; Rusch, T.; Krekiehn, N. R.; Bloedorn, A.; Magnussen, O. M.; Herges, R. ChemPhysChem 2016, 17, 1870-1874. doi:10.1002/cphc.201600147

20. Schlimm, A.; Stucke, N.; Flöser, B. M.; Rusch, T.; Krahmer, J.; Näther, C.; Strunskus, T.; Magnussen, O. M.; Tuczek, F. Chem. - Eur. J. 2018, 24, 10732-10744. doi:10.1002/chem.201800911

21. Lemke, S.; Ulrich, S.; Claußen, F.; Bloedorn, A.; Jung, U.; Herges, R.; Magnussen, O. M. Surf. Sci. 2015, 632, 71-76. doi:10.1016/j.susc.2014.08.028

22. Rusch, T. R.; Hammerich, M.; Herges, R.; Magnussen, O. M. submitted for publication.

\section{License and Terms}

This is an Open Access article under the terms of the Creative Commons Attribution License (http://creativecommons.org/licenses/by/4.0). Please note that the reuse, redistribution and reproduction in particular requires that the authors and source are credited.

The license is subject to the Beilstein Journal of Organic Chemistry terms and conditions: (https://www.beilstein-journals.org/bjoc)

The definitive version of this article is the electronic one which can be found at: doi:10.3762/bjoc. 15.175 